\title{
Sistema municipal de gestión de calidad. La aplicación de los modelos de calidad a la gestión pública
}

\section{Antonio Díaz *}

Los principios básicos de la gestión de calidad y de la calidad total —-como estadío más avanzado de este paradigma de gestión- pueden ser perfectamente implantados en la gestión de la Administración Pública, tanto en sus aspectos teóricos, como en su aplicabilidad práctica.

Con una única condición, que podemos tomar prestada de los consejos de Deming - uno de los padres de las teorías de calidad-, de "adaptarn, y no "adoptarn, dichos principios, a las especificidades de la Administración Pública.

Pero además, según nuestra teoría, la gestión de calidad vendría a aportar una serie de novedades, innovaciones, peculiaridades o mejoras al ya largo proceso de cambio y modemización en la gestión de las AAPP, que sin duda van a favorecer la profundización de este proceso.

A lo largo del presente texto pretendemos en primer lugar presentar esos rasgos básicos de la gestión de calidad para mostrar su posibilidad de traslación teórica a las Administraciones Públicas ${ }^{1}$. A continuación veremos cómo entronca la gestión de calidad en el llamado proceso de modernización de las AAPP, y de qué manera en la práctica cotidiana de una Administración Local —el Ayuntamiento de Alcobendas - se articula un sistema municipal de gestión de calidad, apto además —creemos- para ser aplicado en otras Organizaciones Públicas de naturaleza similar.

\section{La Calidad: perspectiva} histórica

El fenómeno de la calidad, o lo que ahora se denomina "movimiento internacional por la calidad", alcanza su notoriedad vinculado a la revolución industrial japonesa tras la Segunda Guerra Mundial, si bien casi todos los autores coinciden en señalar sus antecedentes en USA durante dicha guerra, donde las técnicas y herramientas de control de calidad se desarrollan extraordinariamente al objeto de proporcionar suministros fiables y rápidos a la industria bélica.

Originariamente, la calidad nace vinculada principalmente al concepto de control de calidad, y más concretamente al control estadístico de procesos de fabricación o producción industrial, en el marco de los paradigmas tayloristas imperantes en ese momento. W.A. STEWART publica en 1931 Economic Control of Quality of Manufactured Products, trabajo considerado como el primer hito en la historia de la calidad.

Otro evento lo constituirá en el año 1947 la fundación en Londres de la International Organization for Standardization, que se ocupará en el desarrollo de normativas a cumplir por los diferentes productos industriales, y cuyos trabajos desembocarán muchos años después en la publicación de las famosas normas ISO.

La introducción en Japón se realizará de la mano de los profesores y consultores americanos, considerados ya como clásicos en la materia, Deming y JuRán, que, invitados por la Industria de telecomunicaciones y por la Asociación japonesa de científcos e ingenieros, realizarán sucesivos viajes a partir de 1949 , impartiendo seminarios, conferencias y los primeros cursos de calidad que van a generar una inquietud e interés inusitados en una industria y un país deseosos de corregir los déficit de calidad en sus productos y recuperar el nivel de su maltrecha economía tras la segunda gran guerra.

Los japoneses van a inventar un nuevo concepto de calidad, más allá de la idea de "control" estadístico de procesos o pro- 
ductos. La carencia de materia prima como bandicap para su desarrollo, y la necesidad de evitar el despilfarro, les lleva a un esfuerzo enorme en la mejora del diseño de sus productos, antes aún de comenzar su fabricación. Así, mientras el énfasis del control de calidad en Occidente se aplicaba a posteriori, los japoneses lo empiezan a colocar a lo largo de los procesos de fabricación, e incluso antes, en el diseño previo. Aquí comienzan las claves de algunos conceptos de calidad que con el tiempo serán imperantes en todo el mundo:

- Mejora del diseño (calidad preventiva).

- Implantación de lo que luego se llamaría "cero defectos": hacer las cosas bien a la primera.

- Espíritu de mejora permanente y búsqueda de la eficiencia y el ahorro.

Todo ello, unido a algunas peculiaridades culturales del país y del trabajador japonés, como su disciplina e integración en el trabajo y la empresa, o el ya citado espíritu de mejora continuada (lo que denominan KAIZEN (DE KAI = cambio y ZEN = bondad), ayudan a entender cómo se comienza a configurar esa revolución conceptual, que en una primera etapa se diferencia en esa idea de calidad preventiva que afecta tanto a la labor de ingeniería de diseño, como al análisis de las necesidades y deseos del futuro consumidor (anticipo de la calidad orientada al cliente), y que en posteriores etapas irá configurando realmente un modelo japonés de gestión de calidad, que más adelante se extenderá a Occidente, cuyas características básicas podríamos sintetizar en algunos principios:

- La política de calidad es dirigida por el presidente de la empresa, se le asigna la máxima prioridad, y en ella participa todo el personal y todos los departamentos.

- Las actividades de garantía de calidad abarcan desde la planificación inicial hasta los procesos finales de venta y post-venta.

- La calidad se consigue a través de la formación y educación de los trabajadores.

- La calidad se desarrolla con las actividades de grupos participativos (los famosos círculos de calidad, creados en 1960 por K. ISHIKAWA).

Finalmente, podemos señalar también un cambio radical que introducen los japoneses con la aparición de un nuevo concepto de costes relacionado con la calidad, que según $\mathrm{G}$. TAGUCHI sería "el coste que un producto impone a la sociedad desde el momento de su concepción", lo que lleva a una concepción global según la cual la calidad pretende mejorar la economía y productividad de las empresas, y por ende la economía y la productividad del país, lo que induce directamente a la promoción de las actividades de calidad por toda la nación, antecedente y origen de lo que hoy podemos denomi- nar como movimiento internacional por la calidad, que agrupa o aúna voluntades de gobiernos, empresas, instituciones y particulares $^{2}$

Los éxitos empresariales que han acompanado a las empresas japonesas en las pasadas décadas (años 60, 70 y 80 principalmente), han contribuido sin duda a generalizar en gran medida estos métodos, y sobre todo a retroalimentar teorías y experiencias prácticas de los países occidentales, tanto en USA como en Europa, donde se han ido matizando, adaptando y acuñando también enfoques, conceptos y herramientas para el desarrollo e implantación de la gestión de calidad.

Desde nuestra perspectiva, y aun a pesar del reconocimiento a los logros del sistema y estilo de gestión de calidad "a la japonesa", cabría plantear, al menos, dos grandes líneas de reflexión crítica: en primer lugar, el escaso énfasis en lo que podríamos llamar la perspectiva o situación del trabajador en la organización. Los japoneses se orientan clarísimamente al producto y a la empresa, con una sensibilidad social y empresarial hacia la situación del trabajador claramente diferente a la que podemos encontrar en algunas empresas europeas. Dicho de otra forma, el "contrato social" entre empresa y trabajador japonés es sustancialmente distinto al imperante en Europa tras la Segunda Guerra Mundial. Que la globalización de la economía nos empuje hacia uno u otro modelo dependerá, entre otros muchos factores, de la correlación de fuerzas sociales y políticas en juego en los próximos años en Occidente, así como de los resultados de los diferentes modelos. Las recientes crisis, tanto en Japón como en el sudeste asiático, ofrecen lecturas interesantes en este sentido.

En segundo lugar, apuntaríamos otra línea crítica al estilo japonés, en una suerte de "misticismo" en torno a la gestión de calidad, cual si de una nueva religión se tratase, que redimirá a la empresa y al país de todos los males. Misticismo que también se habría incorporado a occidente, con sus profetas, gurús y toda suerte de líderes espirituales y materiales de la Calidad. Puesto que hablamos de gestión de organizaciones, y no de ideología ni de moral, desde nuestro punto de vista, parecería más propio adoptar una perspectiva sencillamente "laica" al respecto.

Finalmente, cabe también afirmar que el modelo japonés obtiene un desarrollo amplio en las empresas industriales y fabricación de productos, teniendo en cambio escasas o menores experiencias en el sector servicios, donde serán quizás los americanos, y en parte los europeos, quienes van a lograr aplicaciones más exitosas de los sistemas de calidad, espoleados principalmente por las técnicas y herramientas del marketing.

Continuando con la perspectiva histórica de la gestión de calidad, si bien se puede afirmar que en los desarrollos observados en Japón se encuentran prácticamente referenciados al- 
gunos de los principios básicos del enfoque que se dará en denominar como de Calidad Total (TQM), es imprescindible referimos en esta apretada síntesis a lo que se ha denominado aseguramiento de la calidad, como etapa inmediatamente posterior a los inicios con el control de calidad, al que no debemos decir que sustituye, sino que prácticamente lo absorbe y complementa.

Podríamos situar los antecedentes de este enfoque de aseguramiento en la ya mencionada fundación de la ISO en 1947, y más concretamente en la 1. a publicación de la norma ISO 9000 en 1987.

El aseguramiento de la calidad, o garantía de calidad, viene a ser el modo formal que tiene una organización de disponer de un producto bien hecho, y el modo de demostrar esa disponibilidad. Es un concepto que integra prevención y control, constituyendo por tanto un paso más en la evolución del concepto de calidad.

Se trata de disponer de un sistema formal de calidad, capaz de garantizar una normalización de los procesos de trabajo, o de un determinado producto, nacional o internacionalmente va- lidada por organizaciones reconocidas a tal efecto por los gobiernos de los países (entidades de normalización o acreditación) en cumplimiento de familias de normas, también nacional o internacionalmente reconocidas (UNE 45000, EN 29000 e ISO 9000 y 14000 , principalmente). Estas normas serán aplicables a cualquier tipo de empresa para evaluar, como base de partida, su sistema de calidad, con respecto a lo que en ese momento se está haciendo en Europa o en los países más desarrollados.

La Gestión de calidad, desde este enfoque de "Aseguramiento", se complementa con la dotación en la organización de una estructura básica que la sustente, señalada por M. UDAONDO, en los aspectos mínimos siguientes:

* Disponer de una política de calidad, o "directrices y objetivos generales de la empresa relativos a la calidad y expresados formalmente por su dirección generaln.

* Disponer de un sistema de calidad, recogido en documentos técnicos que describirán las características y/o especificaciones de calidad de los productos o servicios, el modo de obtenerlas y controlarlas y lo relativo a la optimización y mejora permanente del sistema.

* Disponer de una estructura jerárquica de documentos, donde quede plasmado lo anterior: manual de calidad, planes o programas de calidad - generales o específicos- y procedimientos o instrucciones detalladas y documentadas, que describan las metodologías de aplicación o desarrollo de esos programas o planes de Calidad.

La elaboración de todo este sistema y su puesta en práctica pretende reflejar y constatar que la calidad es algo intrínseco a la organización que lo aplica, que forma parte de su cultura y que está incorporada a su estructura y manera de hacer las cosas, con un compromiso estable de la dirección.

La crítica principal que diferentes autores han venido reailzando a los sistemas de aseguramiento de la calidad está referida a su énfasis en los aspectos más burocráticos o formalistas de la gestión de calidad, despreocupándose -desde este punto de vista - de otros aspectos clave para las organizaciones, tales como costes, resultados o clientes.

No obstante, y aun pudiendo coincidir con esta crítica, no cabe minusvalorar la importancia básica —sobre todo en empresas industriales - de disponer de dichos cimientos básicos para desplegar una política de calidad. Dentro de una Organización, el Aseguramiento sirve sin duda como herramienta de gestión, además de ser un referente claro en situaciones contractuales para establecer la confianza en el suministrador.

Es a partir de estos análisis, y sobre todo de la evolución que las ideas de Deming y JuRán habían experimentado en Japón, y de su vuelta a Occidente, cuando comienza a tomar cuerpo el concepto de Calidad Total, o más concretamente, Dirección de la Calidad Total, "Total Quality Management. (TQM).

También el hecho de que se van consolidando modelos claros de referencia para las organizaciones deseosas de emprender el camino de la calidad. Más allá de las citadas normas ISO, y como modelos más globales, aparecen y se consolidan los premios Malcolm Baldrige a la calidad total en USA, el modelo del premio Deming en Japón, y más recientemente el premio Europeo, referenciado en el llamado modelo europeo de excelencia empresarial impulsado por la EFQM (Fundación Europea para la gestión de calidad)

Se podría definir la calidad total como un uenfoque integrado de gestión que tiene como objetivo la mejora continua de la satisfacción de los clientes - externos e internos- y la disminución permanente de los costes reales" (M.A. HeRAs). Otros autores la definen como una filosofía, cultura o estilo de gerencia de una empresa, según la cual todas las personas en la misma estudian, practican, participan y fomentan la mejora continua de la Calidad" (K. ISHIKAWA).

El concepto de calidad deja de referirse solamente al hecho de "cumplir especificaciones" (CROSBY), para convertirse en "adecuación al uso, satisfaciendo las necesidades del cliente" (JuRán), o dicho de una manera más técnica un grado predecible de uniformidad y fiabilidad a bajo coste, adecuado a las necesidades del mercado" (Deming). Tal y como habíamos comentado, se incorpora básicamente la preocupación por los costes y por los clientes, en una perspectiva de mejora continua, lo que lleva directamente a la consideración de un modelo global o, dicho de otra forma, a la participación de todos y a la integración 
progresiva de la gestión de calidad en el modelo global de gestión de la empresa.

Esta idea de "mejora continua" se debe integrar en la estrategia de la empresa y en su estilo de trabajo. Deming lo explicará comparándolo a un círculo (PDCA = Planear, Hacer, Controlar, y Actuar) que gira sobre sí mismo, repitiendo secuencialmente esos procesos de mejora. JuRán lo expresará a través de su famosa trilogía (Planificar la calidad, Controlar la calidad y Mejorar la calidad), que en definitiva viene a significar lo mismo. Se trata en todo caso de caminar en pos de lo que algunos expertos denominan "espiral de la excelencia". Pero, como señala muy acertadamente UDAONDO, la perfección inalcanzable a la que se debe tender, supone, entre otras cosas, alcanzar la máxima calidad con un coste mínimo, cualidades en ocasiones dificilmente compaginables por lo que las empresas deberán definir ael punto óptimo que supone para ellas un equilibrio entre coste y calidad para el suministro de un determinado producto o servicion. En la adecuada elección de ese punto, y la aceptación que gracias a él otorgue el mercado, radicará, desde un sentido práctico, esa perfección o excelencia empresarial.

Cabe resaltar como elemento diferenciador que esta idea de mejora permanente abarca todas las actividades y todos los departamentos y estamentos de una organización. Ello nos remite a lo que a nuestro entender constituye otro factor clave en la calidad total: la Participación de todos, y no sólo de la Alta Dirección - que lógicamente ha de estar comprometida-, con las enormes implicaciones que ello tiene en la cultura y funcionamiento cotidiano de las organizaciones: el trabajo en equipo, la comunicación interna, la reducción de las funciones de control y auditoria, sustituyéndolas por las de autocontrol y autoauditoría, y la amortiguación de las distancias jerárquicas, aboliendo la atmósfera de culpa y convirtiendo los errores en oportunidades de aprendizaje y mejora. En este campo, la revolución cultural y conceptual que supone para algunas empresas puede ser aún mayor que las señaladas hasta ahora.

Otro elemento claramente diferenciador lo constituye la estructuración del concepto Proveedor-Cliente (la cadena de valor siempre orientada al cliente), como núcleo básico para plantear la gestión y las mejoras, con al menos dos implicaciones claves: la consideración de las organizaciones como conjunto de Procesos orientados al cliente, y la aparición y énfasis en el concepto de "cliente interno", al que hay que satisfacer, para así llegar a satisfacer finalmente al cliente externo.

Resumiendo las diferentes fuentes consultadas, podemos sintetizar en las siguientes como principales características o principios de la nueva gestión de calidad, o lo que algunos autores denominan como Calidad Total:
* Calidad es satisfacción del cliente.

* La satisfacción del cliente tiene que ver con lo que pasa por el producto o servicio. La idea de costes y competitividad está implícita en el concpeto de calidad.

* Las organizaciones han de ser entendidas como procesos orientados a clientes (cadena de valor).

* El cliente está siempre en cada etapa del proceso (cliente interno).

* Cualquier proceso puede ser susceptible de análisis, medición y mejora. Lo que no es analizado ni medido, no puede ser comprendido ni mejorado. El objetivo del análisis es la mejora continua de todos los procesos y actividades de la empresa.

* El proceso sólo puede ser mejorado entre todos los que intervienen en él (participación).

* La mejora de los procesos siempre está orientada al cliente (vuelta al primer principio).

Otro elemento que ha marcado singularidades es la irrupción y aplicación de estos modelos en empresas de servicios, coincidiendo con el auge de este sector y la importancia creciente de su peso específico en el conjunto de la economía. Esto llevará a interesantísimas reflexiones sobre las características, dimensiones y atributos de la calidad en empresas de servicios, e incluso a la definición de un modelo conceptual de "Calidad Total en Servicios" (Zeithmal, Parasuraman y Berri), así como sus dimensiones y necesidad de medición desde la perspectiva del cliente.

Finalmente, cabe también decir que la gestión de Calidad Total, o los modelos globales que hoy actúan como referencia, tienen también sus críticos y se encuentran en permanente evolución —en este momento se está procediendo a la revisión de algunos de los factores y criterios del modelo Europeo de Excelencia- No obstante, casi todos los autores coinciden en señalar cierta progresión histórica en el perfeccionamiento o mejora de esos modelos, y por otra parte en considerar esta evolución como etapas por las que diferentes organizaciones han de pasar $\multimap$ permanecer - dependiendo de sus singularidades.

Como se ve, la evolución histórica de los diferentes modelos de gestión de calidad, la han ido aproximando también a las AA.PP., en tanto en cuanto éstas son en gran medida organizaciones prestadoras de servicios, reconociéndose así fácilmente las utilidades de los modelos de gestión aplicables a cualquier otra empresa de servicios. 


\section{Calidad Total en la Administración}

En el plano teórico, no observamos ninguna dificultad insalvable para poder aplicar los principios citados a la Administración Pública. La única condición, como se ha mencionado al principio, y al igual que ocurre con otras técnicas, herramientas o modelos de gestión provenientes de organizaciones privadas -lo que se ha dado en llamar modelos gerenciales-, es considerar como elemento de partida las especificidades de la Administración, que resumiremos en 3 grandes bloques de categorías:

1. El fundamento básico de que las Administraciones han de servir al interés general, lo que tiene consecuencias en aspectos clave de la gestión. Principios constitucionales como los de transparencia, objetividad, equidad e igualdad de oportunidades, tienen una importancia capital en la gestión pública.

2. El marco jurídico al que está sujeto el conjunto de la Administración, diferente al de las empresas y organizaciones privadas, tiene consecuencias en dos de los principales ámbitos de gestión relacionados con las herramientas de calidad:

- La gestión económica, en la cual los elementos de control y fiscalización, previa o a posteriori, son muchísimo más estrictos y restrictivos que los del ámbito mercantil privado.

- La gestión de recursos humanos, y básicamente las leyes o estatutos de la función pública que regulan dicha gestión, dentro de unos parámetros notablemente diferentes y también mucho más rígidos que los de la legislación común para el resto de organizaciones.

3. La cultura corporativa, y en general el contexto cultural en que se mueven las organizaciones públicas, como consecuencia histórica de las especificidades anteriores, es notoriamente diferente al de las organizaciones privadas. Hasta hace bien poco, y con mucho peso todavía en la actualidad, la cultura del control y la desconfianza primaba en la relación que además se establecía entre "administrador y administrado". En el actual contexto de cambio y adaptación que sufren las Administraciones, es cada vez más emergente una cultura "relacional" y de servicio al ciudadano ${ }^{3}$.

Estos elementos diferenciales o tres grandes bloques de restricciones configuran el quehacer cotidiano y el marco general de adaptación de la gestión de calidad a las Administraciones, y hacen que la labor de los gestores públicos tenga un alto grado de complejidad y dificultad, difícilmente homologable al de las organizaciones privadas.

A partir de aquí, resulta relativamente fácil realizar una traducción o traslación teórica -otra cosa es su puesta en práctica- de los principios y fundamentos de la gestión de calidad y calidad total a las Administraciones:

* Calidad es cumplir con las expectativas y necesidades del ciudadano (analogía con el principio de satisfacción del cliente).

* Lo que el ciudadano quiere tiene una correlación directa o indirecta con lo que paga -tasas, precios públicos, impuestos, ...- (analogía con la idea de costes y el principio de competitividad).

* Las organizaciones públicas pueden ser entendidas y conceúicúas como procesos cuyo fin es satisfacer al ciudadano (cadena de valor orientada al ciudadano).

* El ciudadano está siempre al final de los procesos. Cada una de las etapas hay que concebirla orientada al cliente (principio del cliente interno).

* Cualquier proceso, procedimiento o servicio al ciudadano, puede ser analizado, medido y mejorado (principio de mejora continua).

* El proceso o servicio sólo puede ser mejorado con la implicación y participación de todos los que intervienen en él (principio de participación).

* La mejora estará siempre orientada a las necesidades y expectativas del ciudadano (vuelta al primer principio).

Quizá sea necesario, para finalizar este punto, una breve reflexión sobre las analogías y diferencias entre los conceptos de ciudadano y cliente, debate muy querido, frecuente y común entre expertos y especialistas de estas materias, y que consideramos interesante y nada baladí, aunque a veces escasamente útil desde la perspectiva de la práctica cotidiana del cambio en las AA.PP. Es evidente que el concepto de ciudadano -que alude en última instancia a una suerte de contrato social y a la relación entre el individuo y el Estado- es mucho más amplio, global y complejo que el de cliente -que alude a una relación mercantil entre ofertante y demandante-, remitiendo por tanto al mercado y a un determinado modelo de intercambio, que no tiene por qué ser, y de hecho no lo es, - por mucho que la hegemonía ideológica liberal lo trate de imponer-, paradigma universal y válido para cualquier relación, mucho menos para las relaciones sociales y de ciudadanía.

El ciudadano es ante todo un sujeto de derechos, y así debe ser considerado globalmente en la relación con el Estado, desde nuestro punto de vista. A partir de ahí, y según la posición o 
Sistema de Callidad

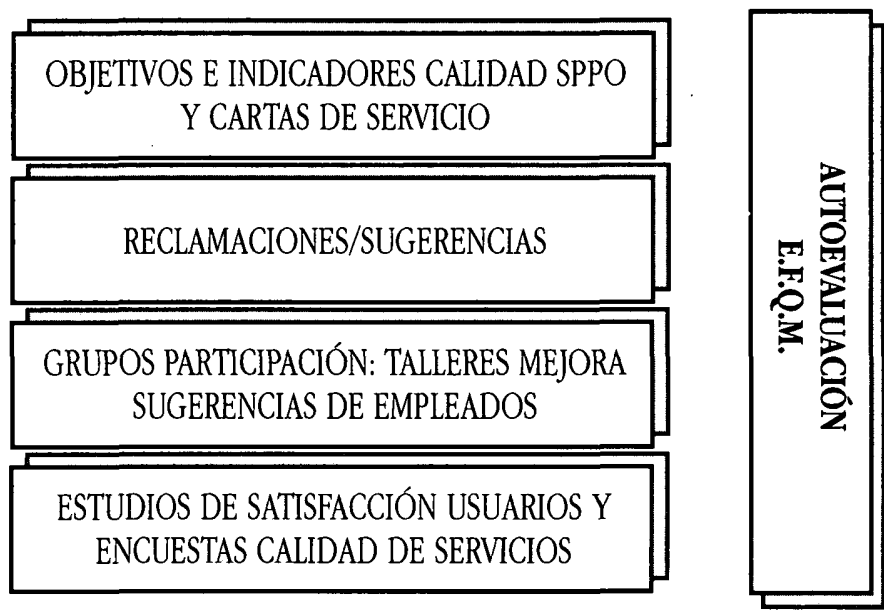

el momento en que interactúe o se relacione con la Administración, el ciudadano - siempre sujeto de derechos y más o menos partícipe en los asuntos públicos en función de un dinámico y cambiante concepto de ciudadanía-, actuará indistintamente como ciudadano-contribuyente, ciudadano-usuario de determinados servicios o prestaciones de la Administración, o directamente como ciudadano-cliente cuando interactúe directamente con un empresa u organización pública mediante un pago directo por servicio recibido, máxime si existe posibilidad de elección.

Rebajar el ciudadano a mero cliente acarrea algunos efectos que podríamos considerar "perversos", como la discriminación entre "buenos y malos" clientes en función de su capacidad de compra de servicios, perdiendo de ese modo la perspectiva global de lo público y del "interés general". Además, difícilmente podríamos aplicar la consideración literal de "cliente" a algunos de los usuarios de servicios de las Administraciones como por ejemplo la población penitenciaria, o sencillamente aquellos casos donde no se dé la libertad de concurrencia o la posibilidad de elección.

Es por ello que abogamos abiertamente por la denominación genérica de ciudadano, como marco general de la relación del individuo con el Estado, y a partir de aquí y según la posición que ocupe en esa relación o del momento en que ésta se produzca, hablaremos de: ciudadano a secas, cuando se plantea una relación puramente inștitucional de referencia, o ciudadano-contribuyente, ciudadano-beneficiario, ciudadano-usuario o ciudadano-cliente, según cual sea ese momento o esa posición en la relación.

A partir de esta reflexión y consideraciones de adaptación, podemos siempre hacer la traslación conceptual señalada, y quizás una de las mayores revoluciones conceptuales en las AA.PP en los últimos años, y uno de los principales vectores de los procesos de modernización y cambio en las AA.PP. ha sido la visión e incorporación del concepto de ciudadano como cliente, dando pie a la incorporación de las técnicas y modelos gerenciales, entre los que se encuentran precisamente la gestión de calidad a la que hacemos referencia. Sin duda ninguna, la "metáfora del cliente ha constituido y constituye uno de los elementos e ideas fuerza más importantes para el cambio cultural en las AA.PP.

\section{Modernización y Calidad en la Gestión Pública}

Todos los principios anteriormente citados pueden ser, y ya lo están siendo en algunas organizaciones, aplicados parcial o totalmente a las Administraciones, en el contexto de sus procesos de cambio y Modernización Administrativa. Abandonada la ideología y la práctica de la reforma global y total de la Administración apoyada en un cambio legislativo integral, hace tiempo que desde diferentes gobiernos, en diferentes países, y con muy diferentes ritmos e intensidades dependientes de las voluntades políticas, se ha adoptado la estrategia del cambio progresivo, sostenido y apoyado en medidas complementarias: jurídicas, culturales y sobre todo de gestión, que se ha dado en llamar "modernización" y uno de cuyos principales vectores ha sido la introducción de la idea de cliente y de los citados modelos gerenciales. Como señala muy acertadamente CroziER, en este 
tema es bastante retórica la dicotomía entre reforma y ruptura, pues auna verdadera y persistente reforma constituye siempre una ruptura. Los cambios en profundidad en organizaciones burocráticas y tan firmemente consolidadas como las AA.PP. no se hacen de un día para otro; se necesita tiempo y continuidad en el empeño, además de una voluntad y capacidad técnica y profesional suficiente, acompañada de proyectos políticos claros y de futuro -estratégicos- sobre el modelo de transformación de la Administración que el poder político desea impulsar y desarrollar. Es necesario, además, entroncar y conectar con las corrientes reformadoras y transformadoras de la Administración ya en marcha. La introducción de la gestión de calidad es en este contexto un paso más en ese ya largo proceso modernizador, que no nos podemos permitir desperdiciar ni desaprovechar, si queremos de verdad consolidar el cambio y orientarlo a las necesidades del ciudadano.

Tres grandes corrientes intelectuales y académicas de fondo confluyen en reflexionar sobre este proceso de cambio: las impulsadas desde el Derecho Administrativo, las provenientes de la Ciencia Política y de la Administración, y las impulsadas desde las Ciencias de la Gestión (Management) y la Sociología de las Organizaciones.

También muy diferentes autores y publicaciones de diferentes países vienen dando cuenta de este movimiento modemizador, tanto desde la teoría como desde la práctica, coincidiendo básicamente en que se trata en gran medida de una estrategia de adaptación y supervivencia de las propias Administraciones a las presiones y demandas del entorno.

La situación del entorno o razones sociológicas que se encuentran detrás de la actual preocupación por la calidad en las AA.PP. son las mismas que fundamentan o están en la raíz de la modernización, y que resumiremos en los 4 aspectos siguientes:

1. Existe una crisis de legitimidad de lo público, mientras asistimos a unos cambios evidentes en el papel del Estado. Todo ello ha sido planteado con crudeza por la doctrina neoliberal, apoyada en los diferentes errores y límites del modelo burocrático. Frente a esta realidad hay una clara respuesta y apuesta neoliberal (reducción del Estado a "mínimos", y confianza más o menos ciega en el mercado como paradigma regulador de las relaciones, no sólo mercantiles, sino también institucionales), y una serie de respuestas en dirección contraria que apuntan, a partir de un claro reconocimiento del cambio en el papel del Estado y emergencia de otros modelos (Estado Relacional), al desarrollo de nuevos modelos de Administración y de gestión de lo público, y a la necesidad de mostrar una nueva "eficacia social" 0 eficacia democrática" del sector público en su conjunto.
2. Los cambios en el propio papel del individuo frente al Estado, con la emergencia y preponderancia en la sociedad occidental de las llamadas nuevas clases medias. Las coaliciones ideológicas, culturales, estructurales y políticas en torno a estas clases medias, son las que decantan además las mayorías electorales y los proyectos de gobierno, por su creciente capacidad de presión y su capacidad instrumental de condicionar a través del voto dichas mayorías.

3. Las incertidumbres de la globalización y la emergencia de una sociedad en red o redes de diferente tipo, muy unido a los retos que plantea la nueva sociedad de la información y la irrupción de nuevas tecnologías con capacidad de inducir cambios radicales en la relación entre el ciudadano y la Administración. Es en el terreno de estas nuevas redes donde se están jugando también las batallas ideológicas y culturales, y la capacidad de adaptación o no de las Administraciones.

4. La ruptura de la comunidad política tradicional, con nuevas y sucesivas interdependencias y fragmentaciones, que obligan a constantes coaliciones, y la aparición de la actual competitividad entre Estados, naciones, regiones y ciudades; y entre las propias Administraciones y sus departamentos, así como entre estos organismos y el sector privado, con la consiguiente competencia por recursos limitados y por tanto conciencia de escasez de los mismos. A todo ello no es ajeno, evidentemente, la actual preponderancia de la lógica económica sobre la lógica política.

Éstas son algunas de las principales razones de fondo que obligan y condicionan el cambio en las Administraciones, y a las que las estrategias de Modernización vienèn a dar respuesta. La Calidad supone, desde este punto de vista, un paso más en esta estrategia de fondo de irrupción de la "nueva gestión pública", que se ha desarrollado con diferentes enfoques en distintos países, desde el "eficientismo" británico que llevó a las primeras cartas de servicio, a los intentos de "reinvención del gobierno" de Al Gore en USA.

El antecedente más inmediato de introducción de este enfoque en la Administración, lo encontramos ya a finales de los años 80 con la aparición del concepto de "Receptividad Administrativa". Es en un documento oficial de la OCDE, editado en nuestro país por el Ministerio de Administraciones Públicas, y con notable impacto en las Administraciones de los países miembros, desde donde se propone una nueva concepción de la Administración Pública que pretende abandonar la noción de relación entre administrador y administrado, para considerar que la Administración es un servicio cuyo cliente es el públicon. Se introduce claramente y por vez primera de forma oficial la noción de cliente y se lanza como idea de futuro la "Administración Receptiva", que debe ser: 
- Comprensiva y comprensible (transparente, entendible, con procedimientos sencillos y simples, con un comportamiento presidido por la ética y el reconocimiento por la Administración de sus obligaciones y responsabilidades hacia el ciudadano).

- Responder a las necesidades de los ciudadanos (contar con su opinión, tanto en la acción de gobierno, como en la aplicación y desarrollo de las políticas por las Administraciones).

- Accesible (fácil para relacionarse, en horarios, formas de comunicación, cercanía, ...).

- Fomentar la participación activa de los ciudadanos.

Como vemos con toda claridad, se avanzan nociones y conceptos totalmente concordantes con los principios de la Gestión de Calidad. Anteriormente, encontramos implantaciones relacionadas con el control y aseguramiento de la calidad en Ministerios como Defensa y Agricultura, vinculados a sus respectivos sectores (militar y agroalimentario), así como esfuerzos sostenidos durante las últimas legislaturas desde el Ministerio de Industria con el impulso de planes nacionales de calidad industrial. Más recientemente, y en sintonía directa con el concepto de receptividad, es destacable la experiencia del Observatorio para la Calidad en las Administraciones (MAP), así como desarrollos quizás más amplios en algunos Organismos Autónomos, Comunidades y Ayuntamientos. No es por tanto la Gestión de Calidad nada absolutamente extraño en las Administraciones, y menos aún si nos situamos con cierta perspectiva en los procesos de Modernización y Cambio de las mismas.

Situados en este punto, cabe preguntarnos por las especificidades que aportaría la gestión de Calidad a las Administraciones, o, dicho de otro modo, dónde podríamos situar aquellos aspectos en los que la gestión de calidad puede influir de modo más rotundo en el proceso de cambio de las Administraciones.

Encontramos también aquí 4 aspectos en los que la gestión de Calidad supone un aporte o una profundización notable en este proceso modernizador:

\section{El énfasis en el cliente}

La clara orientación al mercado y a las necesidades del ciudadano-cliente, ya introducidos en la Administración por el Marketing público y desarrollados en el enfoque de aAdministración Receptivan (OCDE), encuentra otra vuelta de tuerca en la gestión de Calidad.

El enfoque de Calidad nos obliga a definir y precisar en cada caso quien es nuestro ciudadano-cliente, así como a plantearnos una serie de preguntas consecuencia de la anterior, so- bre nuestros segmentos específicos de clientes, en función de las prioridades públicas.

La respuesta a la pregunta de ¿quién es o quiénes son nuestros clientes?, realizada en cada Administración, Organismo o Departamento Público, nos obligará a afrontar una serie de cambios y a reorientar, en muchos casos, nuestro modelo organizativo de funcionamiento y nuestras propias tareas, si de verdad queremos enfocar a las necesidades de ese ciudadano el conjunto de trabajos de nuestra organización.

Pero no sólo eso, sino que una vez conocidos y concretados estos segmentos de ciudadanos-clientes, la gestión de calidad nos obliga a conocer, escuchar y medir periódicamente sus necesidades y demandas, así como su evolución, para posteriormente dar respuesta desde los Departamentos y servicios de la Administración.

Conocer nuestro "mercado", conocer nuestro público (conocer a nuestros "competidores", si los hay), y ofrecer respuestas en función de sus expectativas. Calidad en lo público es lo que el ciudadano quiere.

Quienes queremos reformar, modernizar o cambiar lo público, no podemos sino recibir con euforia esta orientación. Tenèr siempre presente al ciudadano y responder con agilidad a la evolución de sus demandas puede estar en la raíz de una nueva idea de ciudadanía, también más participativa (si el ciudadano ve que la Administración le hace caso, participará más). Ya no es el Estado y sus tecnócratas - solos- quienes a priori definen lo que êl ciudadano necesita o no, transformándolo en ordenamientos y servicios o prestaciones, sino que el Estado y la Administración están obligados a "pulsar" permanentemente la opinión y expectativas de los ciudadanos. Esto abre numerosos caminos y perspectivas —entre ellas la posibilidad de emergencia de ese nuevo concepto de ciudadanía, con reconocimiento de derechos individuales y los cauces para su desarrollo-, y abre también incógnitas y nuevas situaciones, como la capacidad de presión o incidencia que puedan tener colectivos poderosos de usuarios o clientes para forzar modificaciones y prioridades en la oferta de servicios de las AA.PP.

A estas complejidades se ha de enfrentar la nueva gestión pública, y para ello lógicamente hay que desarrollar nuevas aptitudes y capacidades en sus profesionales, aparte de cambios culturales importantes (no ha lugar ya la posición de adespotismo ilustrado", tan presente aún en técnicos y funcionarios de la Administración, en su relación con el público).

Sin duda, el énfasis en la noción del ciudadano como cliente, que el enfoque de calidad nos aporta y profundiza, y sus consecuencias en las prácticas cotidianas de lo público, supone y supondrá aún durante mucho tiempo un vector de cambio y transformación potentísimo de estas organizaciones. Desde nuestro punto de vista, habrá que estar muy atentos a los efec- 
tos que este enfoque produce en la gestión cotidiana, y dar nuevas respuestas a nuevos problemas o efectos perversos que pudieran aparecer. Todo ello no invalida para nada la consideración de este vector como positivo en la orientación actuaal de los procesos de cambio.

Por otra parte, la gestión de calidad -en este sentido- habría de completarse o complementarse con otras herramientas provenientes también de los modelos gerenciales, como por ejemplo la Dirección por Objetivos. Si la Gestión de Calidad pone el énfasis en el cliente-ciudadano, la gestión por objetivos lo pone en el cliente institucional o más directamente en el cliente-político (es decir, en el equipo de gobierno). Esto supone un contrapeso ideal y la posibilidad de que no pierda juego o capacidad de maniobra el "proyecto político", como generador permanente de orientación y prioridad de la acción administrativa, pues ése sería uno de los posibles efectos perversos de una preponderancia absoluta de la visión de cliente. También permite y facilita la prevalencia y el respeto al ordenamiento jurídico, como objetivo de la organización. Desde nuestro punto de vista, lejos de contraponer en este caso como modelos alternativos e incompatibles los de Calidad y Dirección por Objetivos -como parecen pretender algunos autores-, diríamos que son absolutamente complementarios, al menos desde la óptica de lo público.

\section{2. Énfasis en los procesos}

La Gestión de Calidad y Calidad Total pone de relevancia permanentemente la organización entendida como un proceso orientado al cliente y basada en la cadena cliente-proveedor, cadena que podemos aplicar tanto a los procesos internos de la organización como a los externos. Este enfoque resulta también particularmente enriquecedor para las Administraciones.

Formalizar con máximo rigor, documentar y normalizar, simplificando la mayoría de los procesos, es una clara vía de mejora de lo público. En este sentido no es nada desdeñable la utilidad y conveniencia de normalizar algunos de estos procesos clave, en la vía del aseguramiento de la calidad, y plantearse la obtención de certificaciones y/o acreditaciones correspondientes, como ya lo están haciendo algunas Administraciones, y como lo hacen con frecuencia algunas de las organizaciones privadas que caminan hacia la excelencia.

La noción de cliente interno aporta también innovaciones radicales de cara a su extensión, particularmente en algunas de las Áreas más burocráticas e internas de las Organizaciones Públicas (Contratación, Tesorería y Área Económica, Recursos Humanos, Organización-Planificación, ...). La extensión de este concepto con éxito en esos Departamentos que no reciben, o lo hacen de forma muy limitada, la presión del ciudadano o cliente externo, puede tener alcances realmente revolucionarios para la eficacia y eficiencia de las AA.PP.

Finalmente, el desarrollo de este concepto en la compleja relación global con proveedores que la Administración tiene, y un enfoque mucho más profesionalizado de la misma - no sólo en la agilización de los plazos de pago, sino en el conjunto de la relación - tiene obviamente notable impacto y alcance para el cambio en las AA.PP.

Aquí, al igual que en el punto anteriormente señalado, cabe también la reflexión sobre la oposición entre una excesiva prioridad hacia "procesos", frente a un énfasis en "los resultados", típico de otros modelos de gestión como la DPO. El contrapeso a determinados efectos perversos que pudieran producirse en aplicaciones o desarrollos burocráticos de la normalización o del aseguramiento de calidad en procesos, ya sea por requerimientos del cliente externo o del interno, también hace aconsejable la complementariedad entre ambos modelos.

\section{3. Énfasis en la participación}

La participación es otro elemento crucial para la definición y desarrollo de la noción de calidad en lo público. Particularmente el enfoque de Calidad Total ha desarrollado notablemente la filosofía y herramientas de participación de los empleados (círculos de calidad, grupos de progreso, comités estratégicos, sistemas de sugerencias, ...) como claves para la consecución de la Calidad Total. Desde el punto de vista de lo público, este concepto cobra una mayor relevancia por tratarse de plantillas de funcionarios o empleados cuya permanencia en la organización está garantizada, y además por la dificultad de desarrollar otros mecanismos de motivación o incentivación más propios de las empresas. La satisfacción del empleado público en su trabajo es un elemento clave para la satisfacción del ciudadano.

Desarrollar y adaptar a la Administración las diversas técnicas de participación individual y colectiva de los empleados públicos (grupos y talleres de mejora, descentralización de la toma de decisiones, clima adecuado, mecanismos de propuesta y sugerencia individual y colectiva, ... etc.) es una vía clara de mejora continua.

La participación, junto con la estabilidad en el empleo, pueden constituirse en elementos claramente diferenciadores de la calidad del trabajo en lo público, siempre que se oriente a la calidad del servicio al ciudadano.

Por otra parte, la participación de los ciudadanos en la gestión de los servicios, y en su funcionamiento, tanto de forma individual (a través de sistemas y cauces ágiles de Reclamaciones y Sugerencias, con capacidad de respuesta rápida), así como otros métodos de participación colectiva (consejos consultivos, 
gestión compartida, participación de entidades en los órganos rectores de organismos públicos, ...), constituyen sin duda otro elemento dinamizador y un agente de cambio para las propias Administraciones, además de abordar otra cuestión clave, como es corregir los "déficit de legitimidad" desde el punto de vista democrático. Hacer más cotidiana y veraz la participación ciudadana contribuye sin duda al refuerzo de la legitimidad de lo público, además de facilitar, si se gestiona adecuadamente -y las técnicas de calidad•vuelven a dar un importante aporte-, la calidad del servicio.

Calidad en lo público es participación del funcionario -que es el que hace funcionar la Administración- y del ciudadano -que es el que hace posible que la Administración exista-.

\section{4. Énfasis en los costes}

Lo público también necesita ser competitivo, justificarse claramente si no quiere correr el riesgo de desaparecer. La comparación entre diversos organismos y con el sector privado está a la orden del día.

También en la Administración, la calidad no puede ser en modo alguno ajena a los costes. Lo que queremos o esperamos de los servicios públicos tiene que ver con lo que nos cuestan, y cada vez más, los ciudadanos hacemos esa reflexión, directa o indirectamente trasladamos a nuestra relación con la Administración la noción y correlación calidad-precio.

Impuestos, tasas y precios públicos tienen que ser necesariamente contemplados y correlacionados con los estándares de calidad y servicio que ofrecemos.

La calidad en lo público significa también encontrar ese punto óptimo de equilibrio entre las características de la oferta y lo que a cambio se le está demandando al ciudadano. Evitar despilfarros - $\tan$ frecuentes en lo público-, repetición de tareas - acercándonos al "cero defectos" en los procesos-y, en definitiva, ajustar y equilibrar permanentemente los costes.

Calidad en lo público no significa ser los mejores, ni los que ofrecen más servicios, ni mucho menos ser los que ofrecen servicos más lujosos. Calidad significa ofrecer lo mejor para tus ciudadanos-clientes, en el punto de equilibrio que ellos mismos van expresando y que el gestor público debe conocer y estar atento a su evolución, con la complejidad de gestión que esto puede significar.

Y este aspecto tiene que ver además, paradójicamente, con la capacidad redistributiva y de cohesión social de la Administración. Es en la política de impuestos, tasas y precios públicos y su correlación con la calidad de las prestaciones, donde se juega básicamente los equilibrios de un Estado Relacional y con capacidad de redistribuir la riqueza en función del interés gene- ral, y de la mayoría que sustentan el proyecto político que gobierne en cada caso la Administración.

Hasta ahora hemos visto algunos de las principales aportaciones que la gestión de Calidad puede hacer a la Administración. No hay impedimentos conceptuales ni desde luego legales para desarrollar estos modelos en organizaciones públicas, con las salvedades y adaptaciones que se han ido poniendo de manifiesto.

Pero realmente el gran reto de estas iniciativas de innovación y cambio en la forma de gestión de nuestros gobiernos y nuestras burocracias reglamentistas está en la aplicabilidad de los principios, en la continuidad de su puesta en práctica, en la implantación de los cambios y de las nuevas ideas.

Señala Crozier que "las ideas no son nada sin estrategia" y la estrategia es sobre todo la capacidad de sacar el máximo provecho de los recursos de que se dispone, siendo que los principales recursos para cualquier cambio son las personas. Se hace necesario por tanto profundizar en la reflexión, pero sin apartarla de la acción. Ésa ha de ser la máxima virtud de las organizaciones que quieran desarrollar un pensamiento estratégico propio: su capacidad de aprender, relacionando la riqueza de su experiencia práctica, con nuevos enfoques y planteamientos teóricos o técnicos.

La capacidad de escuchar a las personas y colectivos: de escuchar al entorno, y la capacidad de reflexionar, aprender y mejorar a partir de esa escucha y de la propia experiencia, es un rasgo que caracteriza a las organizaciones con capacidad de innovación, y las define y diferencia de otras.

\section{La Implantación de la Calidad en el Ayuntamiento de Alcobendas}

A continuación vamos a describir sintéticamente la experiencia de introducción de un sistema de Calidad en el Ayuntamiento de Alcobendas, a partir de la culminación de un proceso de modernización, que se ha venido desarrollando desde mediados de los años 80 hasta la actualidad, a través de un proceso de cambio organizativo y descentralización de la gestión. El proceso coincide con el propio crecimiento del Ayuntamiento, y se caracteriza además por introducir paulatinamente enfoques gerenciales, en el marco de una cultura relacional y de servicio al ciudadano, impulsada desde el proyecto pulítico. 
Sin entrar a describirlo al detalle, sí parece oportuno señalar los principales eventos de ese proceso de cambio, vistos desde luego a posteriori pues nadie "planificó y programó el proceso de cambio tal y como ahora lo contemplamos, si bieñ sí se puede hablar de una estrategia sostenida, e incluso «dirigida" a partir de 1991. Estos hitos son los siguientes:

- 1984-85 Inicio de la implantación de la Dirección por Objetivos (SPPO).

- 1987-88 Creación del Dpto. de Estudios y primeros estudios sistemáticos sobre asatisfacción de usuarios" en el Patronato Sociocultural.

- 1988-89 Premio Nacional de Deportes y Sports Qualitiy al Polideportivo Municipal.

- 1990 Planes Integrales (Joven, Mujer, ...) y desarrollo de la Coordinación.

- 1991 Creación Centro Gestor: Investigación, Planificación, Organización e Informática.

$1^{\mathrm{er}}$. Seminario Directivo.

- 1992 Descentralización y creación nuevos Patronatos de Servicios.

Creación Comisiones Directivas de Coordinación.

- 1993 Operación Alcobendas 2000. Inauguración nuevo Ayuntamiento. Campaña Derechos Ciudadanos y generalización Sistema Reclamaciones y Sugerencias.

- 1995 Aprobación Plan Estratégico 95-2005: proyecto Calidad.

- 1997 Creación Comité Impulsor Calidad y $1^{\mathrm{er}}$. Plan de Calidad 97-98.

La introducción de un sistema de gestión de calidad, que aparece como línea de fuerza de la modernización a partir del Plan Estratégico y se desarrolla como prioridad en el Plan de Legislatura 95-99, emerge pues de forma clara y rotunda como idea estratégica en un contexto previo de una larga y sostenida experiencia de cambio y modernización administrativa, en la que la Gestión de Calidad supone una nueva vuelta de tuerca, un paso más en dicho proceso de innovación.

La Gestión de Calidad, no aparece pues como un sistema paralelo, ni como apéndice o guinda en una organización altamente burocratizada, ni tampoco como sistema a impulsar en una de las partes de la Organización. La Calidad se entronca en el modelo de gestión del Ayuntamiento, cualquiera que sea el momento de su propio proceso evolutivo.

El Ayuntamiento de Alcobendas es una Administración Relacional, que ha asumido e intenta asumir cotidianamente los cambios que las Organizaciones Públicas necesitan para responder a las demandas ciudadanas.

La misión principal de un Ayuntamiento se puede definir como la de gobernar la ciudad y prestar servicios para el bienestar y la calidad de vida de los vecinos. Para desarrollar esta doble misión, el Ayuntamiento de Alcobendas no ha dudado en introducir modelos gerenciales, en adecuada coexistencia y equilibrio con elementos básicos del modelo burocrático necesarios y consustanciales a la doble misión que el consistorio tiene: gobernar y prestar servicios. Como un municipio relacional en busca de la eficacia social, hemos definido en alguna ocasión a esta Institución.

Es en este contexto, y con un caldo de cultivo adecuado, en el que se ha producido la introducción del Sistema de Gestión de Calidad, que no obstante ha debido pasar por tres sucesivas etapas:

\section{Etapa. Entendimiento y compromiso del equipo dirigente: político y técnico}

Tras la aprobación dentro de una de las 5 líneas estratégicas del Plan Ciudad, se traslada al Plan de Acción Municipal la prioridad en la definición y desarrollo de un Sistema de Calidad en el Ayuntamiento, posibilitando primero la creación de un nuevo programa de Calidad (dentro del Sistema de Planificación y Programación por Objetivos) y posteriormente la creación del Dpto. de Calidad. En dicho Plan 95-99 quedan descritos, escritos y documentados públicamente los objetivos de la política de Calidad, y los plazos para el desarrollo del Sistema. Se definen asimismo proyectos concretos y prioritarios de mejora de la calidad del servicio en la legislatura (Policía, Contribuyente, Oficina de Atención Ciudadana, ...) y se garantiza así la posterior provisión de medios para desarrollar dichos programas en los sucesivos ejercicios presupuestarios.

El compromiso del equipo de gobierno se confirma con varias declaraciones públicas del Alcalde, un documento-declaración escrito y publicado en la revista municipal, y la convocatoria de una 1. o Jornada Interna de Directivos de la Institución ( $1^{\text {er }}$. y 2.ํnivel) sobre "Calidad y Plan de Acción Municipaln, donde se presentan y debaten junto a los objetivos del Plan las líneas maestras del programa de Calidad, intentando informar-consensuar con Directores, Jefes y Coordinadores del Ayuntamiento esta nueva orientación.

El compromiso se corrobora también con la decisión del equipo de gobierno y del Alcalde de solicitar la:adhesión al Club Gestión de Calidad (en ese momento el primer Ayuntamiento de España en realizar dicha solicitud) y confirmar también la anterior adhesión a la Asociación Española de la Calidad. 


\section{2. ${ }^{a}$ Etapa. Creación de la estructura-soporte para desarrollo del sistema}

El programa de Calidad, dentro del Sistema de Planificación y Programación por Objetivos (SPPO) y la posterior creación del Dpto. de Calidad, con 1 técnico especializado en dichas materias, constituyen el embrión de la estructura soporte del Sistema. El verdadero hito lo constituye la creación del Comité Impulsor de Calidad, horizontal a todas las Áreas de la Institución, de nivel directivo, y con participación de un miembro del Comité de Empresa como representante de los trabajadores.

El Comité lo preside el $1^{\mathrm{er}}$. Tte. Alcalde que asiste a todas sus reuniones, y es realmente el órgano de debate, impulso y extensión a toda la Institución de las iniciativas de Calidad.

El Comité Impulsor ha elaborado un Plan de Calidad (9798), actualmente en marcha, con compromisos y plazos de todos los miembros del Comité, que lo han incorporado en sus programas anuales respectivos.

En el marco de este Comité se han debatido todas las iniciativas actualmente en marcha y es realmente el pulmón que impulsa la calidad a toda la organización, y el espacio también para la revisión crítica de los déficit en la extensión de la misma.

\section{Etapa. Elaboración de planes de calidad, objetivos e indicadores de los mismos}

Una vez creados los soportes, el auténtico reto consistía en enlazar el Sistema de Calidad con el sistema habitual de gestión del Ayuntamiento. Funciona en el Ayuntamiento desde el año 85 , con una implantación superior al 90\%, un sistema de Planificación y Programación por Objetivos (SPPO) con elaboración de programas anuales vinculados a los órganos gestores de gasto y a los ejercicios presupuestarios. Todo el Ayuntamiento tiene una programación anual con definición de: objetivos generales y específicos por programa, cronograma de actividades, resultados previstos, indicadores de gestión y elementos de control. La implicación con el sistema de calidad ha sido doble:

- Introducir objetivos de calidad en todos aquellos programas sectoriales que el equipo de gobierno o la dirección han considerado prioritarios. Desarrollo del Plan de Calidad del Comité Impulsor incorporándolo a los objetivos de los programas anuales de cada servicio.

- Requerimiento e indicación desde el Comité Impulsor de Calidad a todas las áreas y responsables de programa, para incluir la medición de indicadores de calidad en todos los programas, y en particular en aquellos considerados prioritarios. En estos últimos, el llamamiento del Comité es a la culminación de dicho proce-
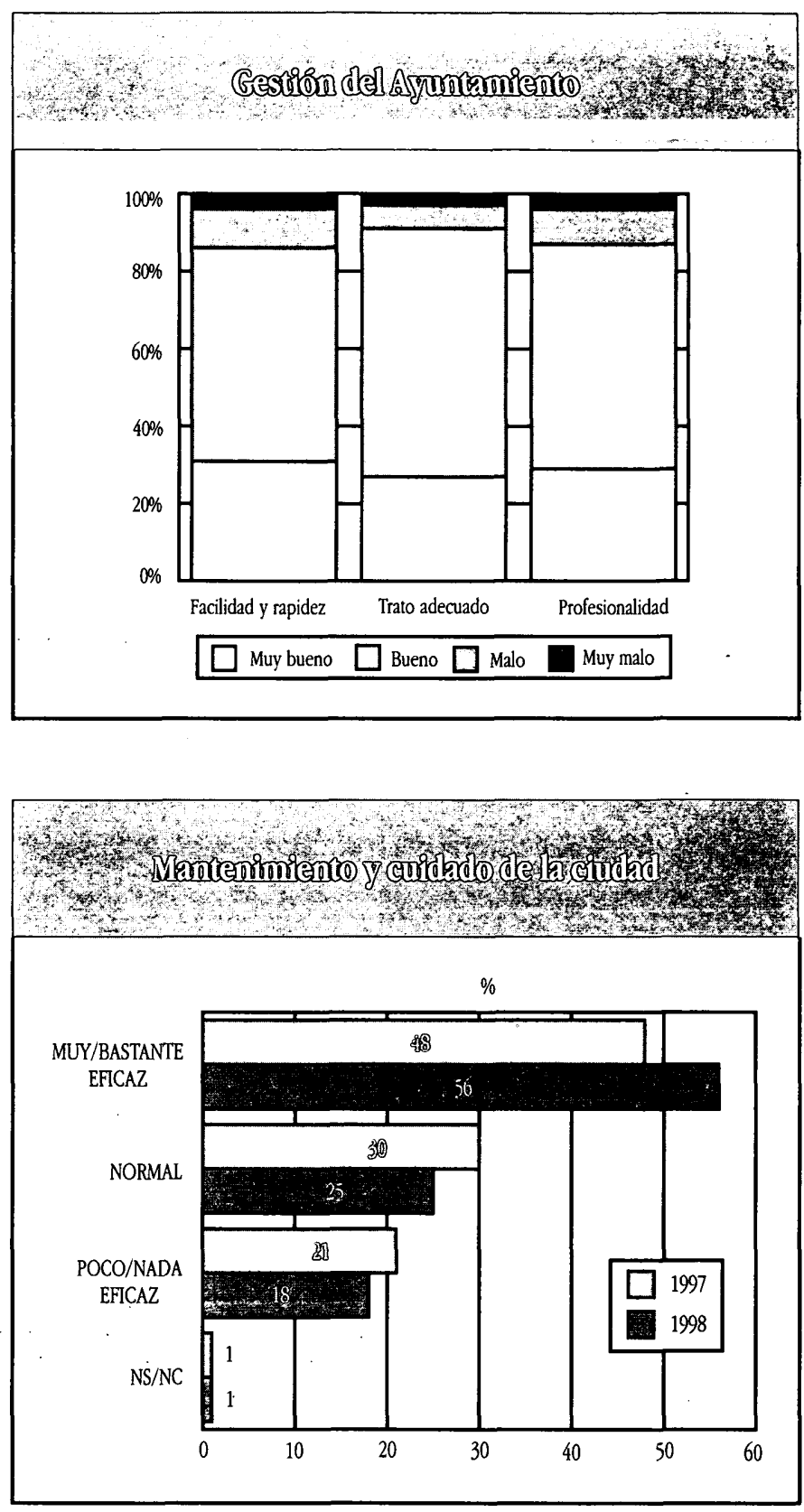

so con la elaboración y presentación pública de Cartas de Servicio en aquellos señalados como prioritarios.

De este modo, y de manera progresiva, se ha ido introduciendo el sistema y herramientas de calidad, sin violentar y complementando el actual sistema de gestión.

Muchas herramientas tradicionales de la gestión de calidad ya se venían utilizando en la Institución. Así, los estudios de necesidades y satisfacción de los ciudadanos que veníamos realizando se han reorientado hacia el modelo de calidad, incorporando una metodología de Calidad Total en servicios con las correspondientes adaptaciones, reconvirtiendo dichos estudios en encuestas anuales de calidad. 


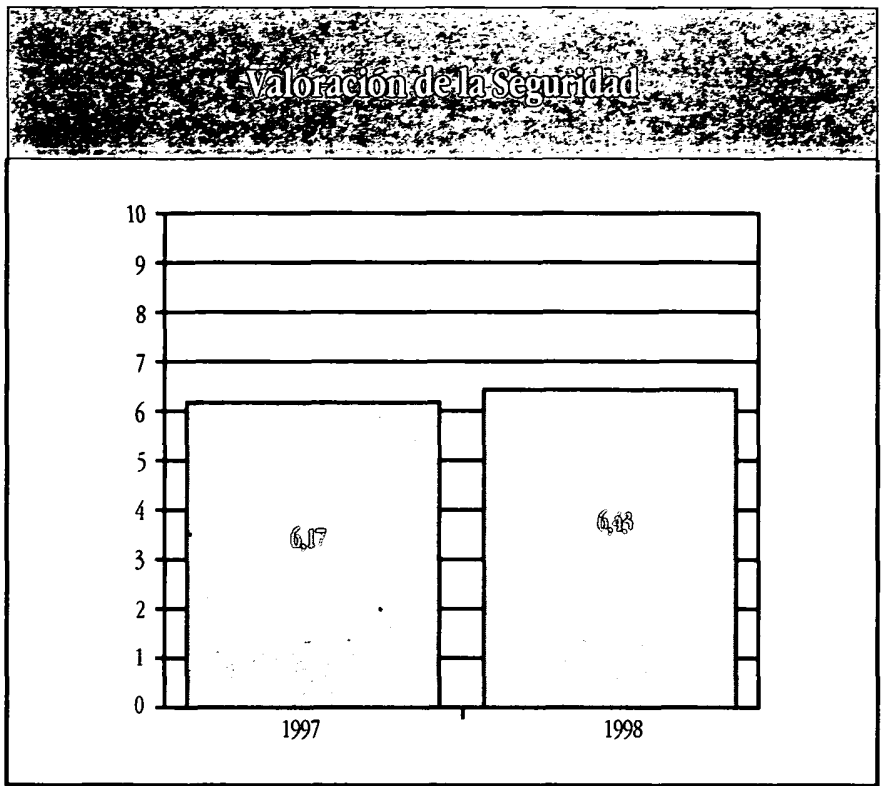

Otras herramientas, sin embargo, han sido totalmente nuevas desde la implantación del Sistema de Calidad. Mención singular merece el sistema de participación de empleados y mejora de procesos a través de grupos de mejora (Planes de Mejora Continua a través de workshops, según la denominación acuñada en nuestra organización por los consultores que colaboran en el programa) ${ }^{4}$. Se trata de la herramienta con la que ponemos en práctica dos de los principios básicos de la calidad total: la organización concebida como procesos orientados al ciudadano, y la idea de que los procesos sólo se pueden mejorar con la participación de todos los trabajadores que intervienen en ellos.

La participación, entendida ésta como compromiso y apuesta de los principales actores que hacen posible la mejora continua en la institución, se convierte de este modo en el eje vertebrador del plan de calidad del Ayuntamiento de Alcobendas.

\section{Sistema municipal de Gestión de Calidad de Alcobendas}

De esta manera, y de forma progresiva y paulatina se ha configurado en Alcobendas, una definición primero, o una manera de entender la gestión de calidad, y a continuación un auténtico sistema de gestión de Calidad integrado con el sistema de gestión por objetivos de la Institución.
Solemos decir que la Dirección por Objetivos más la Gestión de Calidad, contribuyen decisivamente a la satisfacción del ciudadano y a la satisfacción del político. En definitiva, satisfacción de los 2 clientes principales de uná Ádrninistración Relacional.

Lo cierto es que en esta etapa en la que ahora nos encontramos, que podemos definir como de evolución de la Gestión de Calidad hacia la Calidad Total, sí hemos ido configurando unas nociones, un concepto sobre lo que es Calidad en el Ayuntamiento, y un sistema o manera de gestionarla. Consecuencia de ello, también hay unos resultados de los que ya podemos hablar.

"Obtenemos Calidad en el Ayuntamiento de Alcobendas cuando cumplimos con lo que el vecino espera de nosotros. 0 dicho de otra manera, Calidad es acumplir con las expectativas del vecino, que, como se puede observar, es claramente nuestro ciudadano-cliente principal. Sobre esta definición hemos fundamentado el programa de calidad, que implica como consecuencia inmediata otros 3 elementos básicos o principios de partida, que ayudan a precisar nuestro enfoque:

1. - La Calidad está en función de las expectativas del vecino, que por tanto hay que conocer y medir permanentemente.

2.- La Calidad se valora en función de los costes (impuestos, tasas, ...) que hay que ajustar de forma continua.

Dicho de otra forma, lo que el vecino quiere siempre tiene que ver con lo que le cuesta. Y el cómo se distribuyen o redistribuyen los costes de los servicios al conjunto de ciudadanos tiene que ver con la naturaleza del proyecto político.

3. La Calidad se obtiene con participación: de los empleados públicos y de los vecinos, a partir de un compromiso claro y estable de los políticos gobernantes y de la dirección.

Este enfoque queda plasmado y desarrollado en el sistema municipal de gestión de calidad de Alcobendas, que se apoya en 5 líneas de trabajo estables y comunes para toda la Organización Municipal:

\section{Desarrollo de Objetivos, Indicadores de Calidad y Cartas de Servicio}

Con la recomendación a los diferentes departamentos de que dicho desarrollo culmine con la presentación pública de Cartas de Servicio.

Esta línea de trabajo entrelaza el sistema de gestión municipal con el de calidad, permitiendo la incorporación de los objetivos del Plan de Acción Municipal, en el conjunto del sistema de calidad. Se introducen objetivos de Calidad en los programas 
de la Institución, en función de las prioridades políticas o de gestión que se señalen en cada caso. Dado que los programas están asociados a los correspondientes órganos de gestión presupuestario, se hace posible la correlación de dichos objetivos con los costes, incorporando así el enfoque de costes, que es posible obtener y medir con precisión a través de los indicadores de gestión de calidad asociados también a cada programa. El sistema permite, por ejemplo, obtener información periódica sobre costes por plaza o costes unitarios por usuario en una buena parte de los programas y actividades, constituyéndose este elemento como imprescindible referencia en la discusión de las políticas de tasas y precios públicos del ejercicio siguiente, aspecto éste que como hemos visto se considera clave en la definición del enfoque de calidad y de la propia política de gestión de calidad del equipo de gobierno municipal.

Hay programas donde el sistema de indicadores se encuentra ampliamente desarrollado (Patronatos de Servicios y algunas áreas del Ayuntamiento), y otros donde la situación es más precaria, pero la tendencia es clara hacia la obtención de indicadores cada vez mejores, pues esta línea de trabajo se cierra, desde el punto de vista de la gestión de calidad, con la elaboración y publicación de las Cartas de Servicio. Se recomienda desde calidad elaborar Cartas de Servicio allí donde el desarrollo del SPPO ha llevado a un nivel de precisión tanto en los objetivos como en los indicadores, suficiente para poder garantizar a los ciudadanos que los compromisos que se enuncian se controlan periódicamente y se cumplen con rigor. También en ocasiones, y en función de las prioridades del gobierno o de la gestión, se estimula y alienta ese proceso para llegar cuanto antes a esas Cartas, que no son otra cosa más que un documento público y de gran difusión, donde se hacen explícitos los compromisos de Calidad de un determinado servicio o actividad.

La Carta sirve por tanto para estimular un proceso de mejora permanente, y ayuda también a fijar las expectativas de los usuarios en unos estándares determinados, lo cual será también un elemento determinante en la calidad posteriormente percibida. La Carta, finalmente, pretende garantizar el ejercicio de los derechos ciudadanos, facilitando además el ejercicio de los mismos a través de la posibilidad de intervención inmediata si éstos fueran dañados (Reclamaciones o Sugerencias realmente disponibles y accesibles al ciudadano en todo momento).

Las Cartas de Servicio en Alcobendas tienen un proceso de elaboración liderado desde el servicio o programa de que se trate con la ayuda y asesoramiento del Departamento de Calidad. El primer borrador es de elaboración interna y participada, sale del servicio y posteriormente se traslada y es informado y revisado en el Comité Impulsor de Calidad. A continuación se somete a la participación ciudadana en los órganos que correspondan, como mínimo en el "Grupo Impulsor de Calidad" dentro del Plan Estratégico. Finalmente, se publican y difunden ampliamente tanto al conjunto de la población como a los usuarios directamente afectados. Las Cartas actualmente en marcha en el Ayuntamiento de Alcobendas son las de: Policía Local, Atención al Ciudadano, Teatro-Auditorio, Parques y Jardines, Hogares del Jubilado y Actividades e Instalaciones del Patronato Municipal de Deportes.

A modo de ejemplo, los compromisos recogidos en la Carta de la Policía Local de Alcobendas, son las siguientes:

- 6 minutos máximo en respuesta a Urgencias.

- Atención telefónica $24 \mathrm{~h}$.

- Servicio de atención, asesoramiento e información a la - victima.

- Regulación y protección entrada y salida en todos los colegios públicos.

- Retirada inmediata vehículos abandonados con riesgo para la seguridad. 30 días en el resto.

- Hojas Reclamación/Sugerencia en todas las unidades móviles y dependencias.

\section{Participación del Ciudadano: Hojas de Reclamación y Sugerencia}

En todos los servicios, organismos autónomos y dptos. del Ayuntamiento.

Implantado desde 1993 en todo el Ayuntamiento, ya funcionaba anteriormente en algunos servicios del Patronato Sociocultural y Deportivo.

A través de un impreso autocopiativo disponible y visible en todos los espacios de contacto con el público, se pretendía y se ha conseguido convertir realmente al vecino y al usuario de nuestros servicios en un auténtico agente de cambio que nos estimula, critica, ayuda y empuja constantemente a mejorar nuestra gestión, comprometiéndose la Institución a una respuesta en un plazo de 10 días.

Tras más de 5 años de implantación constatamos una evolución del número de Reclamaciones en crecimiento constante hasta situarse actualmente en torno a las 1.000 anuales, de las que cerca de 600 provienen del Patronato Municipal de Deportes, alrededor de 200 de los servicios del Patronato Sociocultural, y el resto del Patronato de Salud e Integración Social y del propio Ayuntamiento. El sistema es susceptible de una mayor implantación en el Ayuntamiento, y se encuentra totalmente incorporado en los Patronatos, donde constituye una herramienta habitual de comunicación, queja, sugerencia, presión y estímulo permanente a la mejora de los servicios desde la perspectiva de los propios usuarios. Funciona cada vez más porque los usua- 


\section{Node Rechamactores}

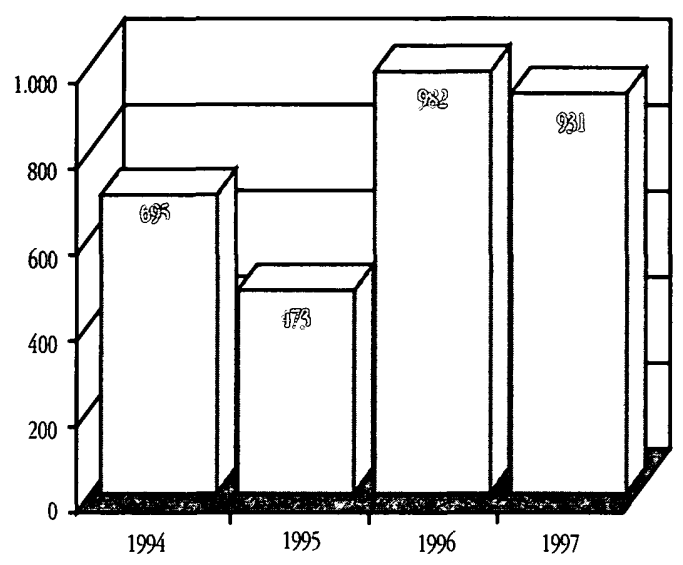

Organoismos allos quee se dirngeon

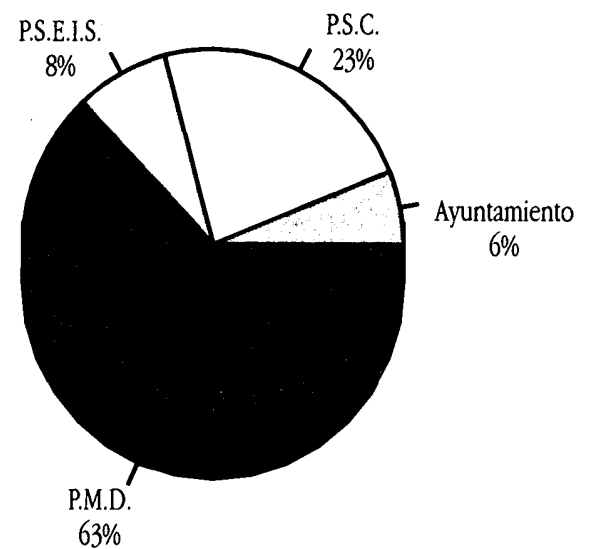

rios saben que se contesta y que en muchas ocasiones la respuesta es además positiva, lo que lleva a veces a su utilización también como herramienta de presión de determinados grupos y colectivos para conseguir mejoras o aperturas de nuevas actividades, constituyéndose en auténticos lobbys de usuarios.

Ha de ser por tanto adecuadamente gestionado en función también de los objetivos generales del servicio, pero sin duda en cualquier caso constituye una poderosísima herramienta de mejora, una manera de tener permanentemente el "pulso del usuario", aunque sea subjetivo, y en definitiva un cauce más para la participación del ciudadano, en este caso del ciudadano-usuario, en la gestión directa de los servicios municipales.
Junto a otros cauces de participación más colectivos (vía Asociaciones o Consejos) este cauce de participación individual refuerza además notablemente la transparencia del funcionamiento del servicio público, e indirectamente hay ün gran tefuerzo de alegitimación del mismo. En el Ayuntamiento de Alcobendas, el lanzamiento de esta iniciativa se acompañó además de una extensa campaña divulgativa de los Derechos Ciudadanos, coincidiendo con el lanzamiento de la Ley 30/92 de nuevo Régimen Juńdico de las AA.PP., ley con un importante componente reformador en alguno de sus aspectos, y que en nuestro caso vinculamos a esa perspectiva de los aDerechos Ciudadanos , reforzando por tanto la visión del ciudadano como sujeto de derechos" en su relación con la Administración, y la de una Administración totalmente areceptiva" y al servicio del ciudadano (enfoque de calidad).

La operativa concreta del Sistema se desarrolla a través del establecimiento de un "circuito" lo más breve y rápido posible para que la Reclamación - una de cuyas copias queda siempre como garantía y con la fecha de entrada en manos del reclamante- llegue en primera instancia a quien tiene la capacidad y la obligación de responder: el área a la que se reclama o sugiere. En segunda instancia llega a Alcaldía y al Área Central de Coordinación del Ayuntamiento, en cuyo Dpto. de Investigación se introduce la reclamación en la base de datos que después permitirá realizar informes periódicos -mínimo 1 anualde análisis sobre las mismas, que se devuelven a las áreas, a todo el equipo directivo y al equipo de gobiemo. De esta forma se incorporan a los procesos de toma de decisión, y se pueden contemplar modificaciones en los objetivos o actividades de los programas del SPPO, como consecuencia de dichas Reclamaciones.

Tras el período transcurrido y las sucesivas series históricas, se va obteniendo información relevante para las áreas y para la toma de decisiones presentes o futuras del Ayuntamiento. Sabemos qué usuarios nos reclaman más, tanto por servicios, por barrios, o por el propio perfil sociológico del Reclamante -así, por ejemplo, nuestro reclamante tipo sería una mujer de entre 25 y 39 años y residente en el Barrio 6-, y sabemos también que temáticas son las más recurrentes.

Actualmente y tras los 5 años de experiencia, las líneas de mejora pasan por la actual revisión e implantación de una nueva aplicación informática que nos permita corregir alguno de los déficit actuales del sistema y cumplir el plazo de respuesta de 10 días en un porcentaje superior al 70\%. También se están integrando en el circuito el seguimiento de reclamaciones que entraban por otros mecanismos (cartas, teléfono, 7 Días e Internet, ...), y se ha realizado un trabajo de perfeccionamiento del estilo de contestación con la edición de una Manual de Atención y Sugerencias-Reclamaciones.

En definitiva, es un mecanismo de escucha y participación del Usuario que nos aporta un input fundamental para la mejora permanente de la calidad de nuestros servicios. 


\section{Participación del empleado público: Talleres de Mejora y sugerencias de empleados}

La participación es, recurrentemente, un rasgo definitorio del Sistema de Calidad del Ayuntamiento de Alcobendas.

La introducción continuada desde el año 96 de la herramienta de los talleres de mejora (los workshops a los que ya hemos hecho referencia anteriormente) refleja, desde el punto de vista de las prioridades del proyecto y también del presupuesto, la apuesta más firme en torno a un determinado enfoque y manera de entender la gestión de calidad desde un Ayuntamiento: a través de la participación de los funcionarios y empleados públicos en la mejora.

Los talleres de mejora ponen todo el énfasis en 2 aspectos: el análisis de los procesos - desde el punto de vista de lo que añade y no añade valor para el ciudadano- y la participación en dicho análisis y mejora de los funcionarios o empleados encargados de su realización cotidiana - por tanto, desde el punto de vista del equipo de trabajo del departamento o servicio-.

Los talleres son auténticas y bastante profundas dinámicas grupales en busca de la propia mejora, en busca de resultados concretos en el propio puesto de trabajo, y a ser posible, a corto plazo y sin requerir inversión. A lo largo de 5 días continuados de intenso trabajo con ayuda de 1 consultor, acompañado de 1 técnico de Calidad, los trabajadores de una unidad analizan pormenorizadamente sus procesos, identificando las pérdidas de valor, las oportunidades de mejora y presentando finalmente un paquete de propuestas de mejora de aplicación inmediata o de corto plazo en el que se comprometen ellos, y se trata de comprometer al resto de la dirección -incluida la dirección política-. Los trabajadores refuerzan su protagonismo y autonomía en el puesto de trabajo y desencadenan un proceso interno de cambio de importantes consecuencias que es necesario mantener, gestionar e impulsar, a la vez que se fuerza la implicación de los diferentes actores de la institución. La herramienta está aportando por el momento resultados excelentes, y los trabajadores que participan se convierten en los principales impulsores hacia el resto del Ayuntamiento.

Tras 6 talleres de mejora realizados (Dpto. de Usuarios del PSC, Oficina Municipal de Información, Servicios Sociales, Dpto. de Tráfico, Dpto. de Industria y Profesores de Actividades Deportivas), hay en marcha en la Institución 6 nuevos planes parciales de mejora continua, totalmente orientados a las necesidades cotidianas de la primera línea de contacto con el público, y hay una auténtica dinámica de participación en marcha, una wola que en este caso avanza de abajo-arriba, desde los equipos de trabajo hacia la dirección. Más de 60 personas de diferentes departamentos y de diferentes categorías -técnicos, auxiliares, administrativos, informadores, ...-, están involucrados en esta dinámica, cuyo primer hito importante es la realización del 11 . encuentro anual de grupos de mejora y participación en este mismo ejercicio, donde se realiza un balance conjunto de la experiencia.

Los parámetros de mejora más usuales son bien tangibles y concretos: ahorros de tiempos de espera o de firmas en las tramitaciones de expedientes, eliminación de tareas de control duplicadas o de registros y archivos duplicados y triplicados en ocasiones, ahorros de desplazamientos a usuarios (envío por correo o gestiones por teléfono), eliminación de colas o reducción notable de tiempos de espera en las mismas, eliminación de causas de reclamaciones, ... etc. Pero quizás lo más importante, y lo que hace que la aplicación en muchos casos sea inmediata, es que todas estas mejoras salen de los equipos. Hay un refuerzo evidente de la dinámica y del trabajo en equipo, quizás un tanto relegado en los últimos años por enfoques excesivamente agerenciales» (o una manera de interpretar éstos), o excesivamente "burocráticos".

La experiencia es sin duda positiva, y la satisfacción tanto de las personas que participan en ellos, como de los responsables y concejales es alta hasta el momento, si bien los compromisos de mejora que se van adquiriendo obligan y comprometen realmente a todos los niveles. Se necesita aún algo más de tiempo, para realmente hacer el seguimiento y balance de todas esas mejoras y su grado de cumplimiento, siendo el reto responder y no frustrar las expectativas creadas y que se van creando en el conjunto de la organización.

Es una apuesta arriesgada y comprometida, tanto para el equipo de gestión como para el equipo de gobierno. En nuestro caso, es también definitoria de una determinada manera de entender la gestión Calidad.

Finalmente, y como complemento de esta línea de trabajo, se ha desarrollado un sistema individual de sugerencias de empleados, también como un circuito y un procedimiento establecido, que debe culminar y apuntar a algún tipo de estímulo y reconocimiento individual para aquellas iniciativas individuales de los funcionarios, orientadas al ciudadano y con aplicabilidad a la mejora del servicio. Es la iniciativa más recientemente aplicada, en la misma línea de fomentar la participación, también de manera individual.

\section{Las Encuestas de Calidad y los Estudios de Satisfacción}

\section{Cómo conocer y medir permanentemente las necesidades y demandas de los ciudadanos}

En Calidad es un aforismo comúnmente aceptado el que dice que alo que no se mide, difícilmente puede ser mejorado. Para ello, como hemos señalado, el Ayuntamiento realiza encuestas con una periodicidad anual sobre la Calidad de los servicios tal y como ésta es percibida por el ciudadano. De esta forma, se obtienen series históricas que nos permiten valorar la evolución de la calidad percibida año a año y servicio a servi- 
cio, valorándose además aspectos significativos de la gestión municipal y de la ciudad (seguridad, limpieza, mantenimiento, ... etc.). Complementariamente, se realizan estudios concretos de satisfacción de los usuarios de un determinado servicio o actividad estable, intentando además indagar sobre los atributos o dimensiones que definen la Calidad de estos servicios, tomando así el pulso a los usuarios de las diferentes instalaciones.

Desde el conocimiento de la gestión global del Ayuntamiento a la valoración y evolución de los atributos que definen la Calidad de vida en la ciudad, se van obteniendo datos, porcentajes y puntuaciones que en definitiva nos están permitiendo conocer más y mejor a los ciudadanos y la evolución de sus expectativas, necesidades y demandas, midiendo la evolución en la satisfacción de los mismos, permitiendo así ajustar y objetivar los estándares de calidad que se ofrecen.

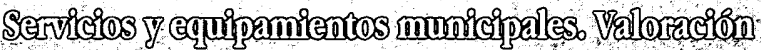

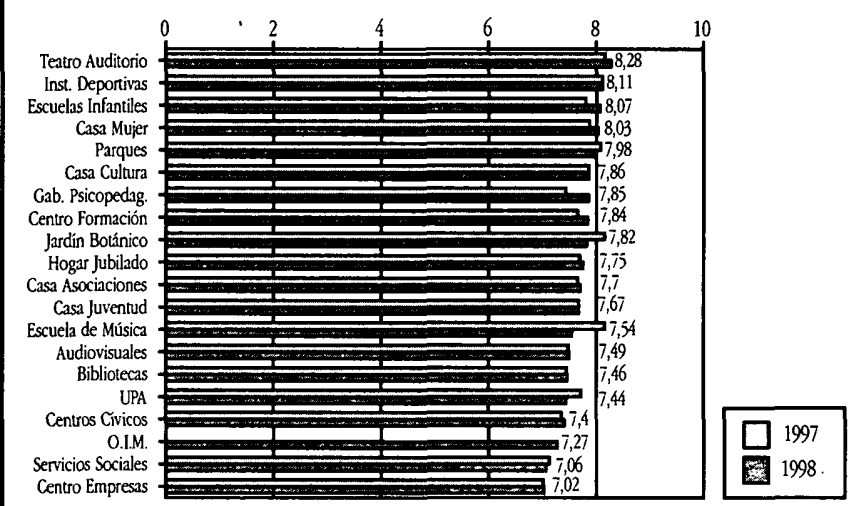

Así, por ejemplo, sabemos que en el año 1997, un $47 \%$ de los vecinos consideran buena o muy buena la gestión del Ayuntamiento, frente a un $12 \%$ que la consideraban mala o muy mala. Sabemos también que un $56 \%$ consideran muy/o bastante eficaz el mantenimiento y cuidado de la ciudad, mientras que un $18 \%$ lo considera poco o nada eficaz, y que en general la calidad de vida en la ciudad obtiene una puntuación del 7'5.

También podemos objetivar que más del $90 \%$ nos dicen que se da un trato adecuado en nuestras oficinas, pero un $14 \%$ nos está pidiendo que seamos más rápidos o ágiles. $O$ por poner un último ejemplo, que en una escala de 0 a 10 , nuestros servicios más valorados por los usuarios son el Teatro-Auditorio, las Instalaciones Deportivas, las Escuelas Infantiles y la Casa de la $\mathrm{Mu}$ jer (todo ello por encima del 8), o que la valoración de la seguridad ciudadana en la misma escala es del 6'4.
Este conocimiento del ciudadano y de los colectivos de usuarios de los servicios, así como de los atributos que para ellos definen la calidad, es el que está en la base y permite al Ayuntamiento de Alcobendas poner los medios para aspirar a satisfacer esa necesidad o demanda y cubrir las expectativas del vecino.

\section{La Autoevaluación según el modelo de EFQM}

El modelo de la EFQM (Fundación Europea para la Gestión de Calidad), como su propio nombre indica, no es un modelo para gestionar, sino para evaluar, o mejor dicho, autoevaluar la gestión de una organización, sea cual sea el enfoque seguido por ésta.

Con este sentido lo hemos utilizado en el Ayuntamiento de Alcobendas, y ensayado en una de las unidades organizativas descentralizadas más importantes, el Patronato Municipal de Deportes. Para cada uno de los 9 criterios $(5$ de Agentes facilitadores: liderazgo, políica y estrategia, gestión del personal, recursos y procesos, y 4 de Resultados: satisfacción del ciudadano, satisfacción del personal, impacto en la sociedad y resultados) en los que el modelo divide esa autoevaluación global de la gestión, y a través de 33 subcriterios que es preciso objetivar de diferente manera, la autoevaluación viene a realizar una auténtica radiografía del estado de salud de la gestión, en relación a un supuesto referente de excelencia empresarial.

Si bien la adaptación al sector público de este autoevaluación, así como del propio modelo, se encuentra en permanente revisión, podemos adelantar, en relación a nuestra experiencia, la utilidad del mismo de cara a obtener esa evaluación global sobre la gestión, junto a los puntos fuertes y áreas de mejora, así como la siempre "referencial" puntuación que al final de su aplicación se obtiene.

Por el método del cuestionario y con ayuda de un consultor externo institucional ${ }^{5}$, tras su aplicación en 2 sesiones amplias de trabajo con el equipo directivo (primero) y posteriormente otras 2 con el equipo de mandos y responsables intermedios, obtuvimos una clara visión de conjunto de la situación del Patronato Municipal de Deportes.

Entre la 1. a y 2. e reunión los participantes rellenaron el cuestionario, realizándose una puesta en común en el equipo directivo, y una presentación y valoración de resultados en el equipo de responsables intermedios. Todo ello permitió una identificación bastante precisa de los puntos fuertes (recursos y satisfacción del ciudadano) así como de las principales áreas de mejora (gestión y satisfacción del personal), donde además carecíamos hasta ese momento de elementos para objetivar esos factores. 


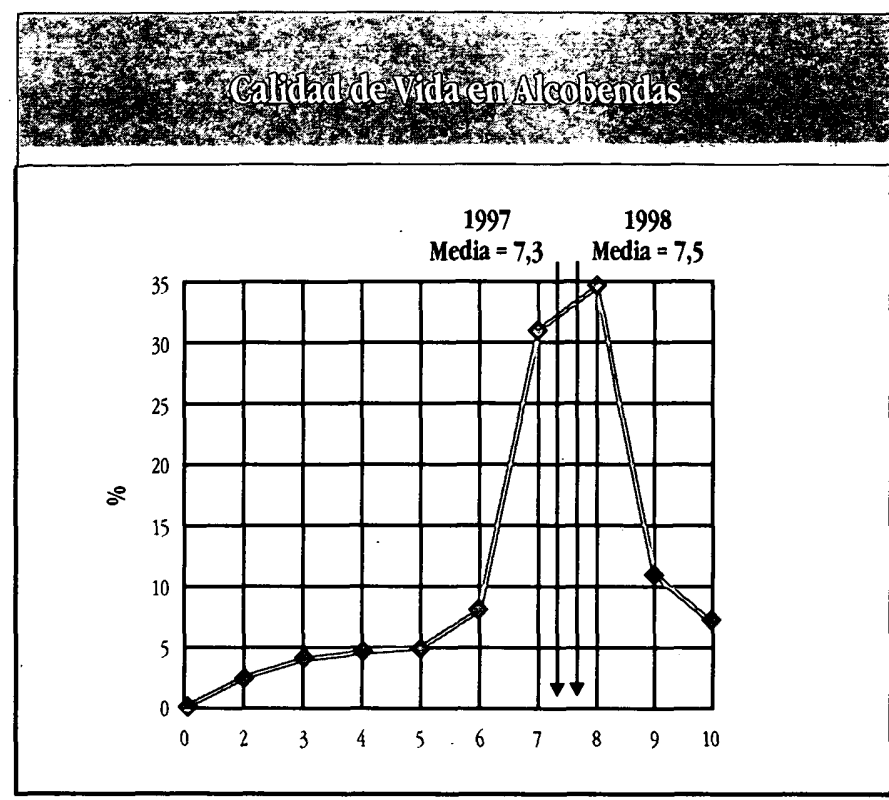

En total participaron 20 personas, y la puntuación obtenida (430 puntos) nos referenció asimismo en relación a otras organizaciones que también usan el modelo, y nos reforzó muy positivamente de cara a la profundización de nuestros planes de mejora, además de constituir un referente para otras partes de la organización.

Hasta aquí, por tanto, el reflejo del sistema municipal de gestión de Calidad que el Ayuntamiento ha conseguido poner en funcionamiento, cuyo sentido último no es otro que conseguir mejores resultados en la satisfacción cotidiana de los vecinos.

Los datos de las encuestas, avalan y refuerzan de momento la utilidad de estos modelos, aparte de señalarnos muy claramente los déficit y los puntos a mejorar, lo que viene o vendrá a retroalimentar los siguientes planes de calidad y mejora continua para los próximos años, en los que ya se está trabajando.

Algunos proyectos concretos, producto de estos esfuerzos de modernización e implantación de la calidad en la gestión, están culminando en estos momentos, como la acreditación este mismo año del Laboratorio Municipal de Alcobendas (norma UNE 66-501), o la culminación también en esta legislatura de uno de los proyectos más ambiciosos en el ámbito de la calidad en la atención al contribuyente (proyecto ALCORE) y de calidad en el conjunto de nuestras Oficinas de Atención Ciudadana: la emisión de la Tarjeta Ciudadana o TARJETA DE ALCOBENDAS, que, junto a la Web ciudadana de información y gestión, están llamados a revolucionar el modelo de atención y relación entre los ciudadanos y el Ayuntamiento.

"Innovar es identificar problemas que aún no se han planteado" (CROzier). Cuando existe un sistema de gestión volcado hacia el ciudadano, y con mecanismos permanentes de «escucha" hacia el entorno y de participación del trabajador, la innovación se convierte en una seña de identidad. No sólo el técnico, el político o el ingeniero, sino el operario o el auxiliar pueden y deben innovar en un Sistema de Gestión de Calidad.

La Calidad se consigue, desde luego, , "entre todos, mejorn, y al margen de sistemas o modelos - siempre importantes-, la calidad se obtiene gracias a las personas que la hacen posible. En el caso de un Ayuntamiento está claro: los políticos que la impulsan, con nombres y apellidos, los directivos y gestores comprometidos en el proceso de mejora continua, y esencialmente los funcionarios y empleados públicos del Ayuntamiento: alos que hacen funcionar" con calidad los servicios municipales.

Todo ello orientado a un compromiso que justifica y fundamenta el esfuerzo de la institución: el compromiso con los ciudadanos.
- Sociólogo. Director de Planificación y Coordinación del Ayuntamiento de Alcobendas.

1 En adelante se utilizará la abreviatura AA.PP.

2 Este movimiento continúa hasta nuestros días y se extiende generalmente impulsado por Asociaciones corporativas, clubs y otras entidades similares que encauzan o lideran estos procesos en los diferentes países e incluso en ámbitos territoriales supranacionales. Bajo la idea fuerza mencionada de elevar la calidad y competitividad de empresas y países, se promueven encuentros, congresos y seminarios, se organizan intercambios, conferencias, premios y actividades de Benchmarking (intercambio y comparación con slos mejores.).

En España, la Asociación Española para la Calidad (AEC) encuadrada en la Europea (Organización Europea para la Calidad-EOQ) y el Club Gestión de Calidad, adscrito a la EFQM (Fundación Europea para la Gestión de Calidad) representan la punta de lanza o vanguardia de este movimiento, en el que participan además numerosas entidades de diferentes ámbitos territoriales.

${ }^{3}$ Son cada vez más los autores que señalan los cambios en el papel del Estado y su relación con la sociedad civil, así como la emergencia de un nuevo modelo de Estado (Relacional), que vendría a completar, superponiéndose, a. los modelos provenientes del Estado de Derecho y del Estado del Bienestar. En consecuencia emerge también un nuevo modelo de Administración que responde a las necesidades de ese Estado y a las exigencias de la llamada Sociedad Civil. X. MEndoza y A. Diaz, entre otros autores, se han referido a estos temas.

\section{${ }^{4}$ I. VILLAR y C. FerNández Abreu. Consultores EURODIRSA, S.A.}

5 J. Cortadellas. Universidad Politécnica de Cataluña. 


\section{Bibliografia}

AEC (1995), Calidad: las cosas claras. Notas para la Alta Dirección. Sección Industrias Energéticas Asociación Española para la Calidad. Patrocinado por MINER-Plan Nacional de Calidad Industrial 94-97.

: IUTOEvaluación (1996), Directrices para el sector puíblico. EFQM. Versión en castellano por el Club Gestión de Calidad.

Bañó, R. y Carrullo, E. (1996), •Productividad y Calidad irespuestas de las AA.PP. para la escasez y la incertidumbre?. En La Productividad y la Calidad en la Gestión Pública, Xunta de Galicia.$$
\text { . }
$$

Castelus, M. (1998), El País, 19 de julio de 1998. Entrevista.

Crozier (1995), ‘La posición del Estado ante los otros actores. GAPP, n.․ 2 .

_(1996), La crisis de la inteligencia. Ensayo sobre la incapacidad de las élites para reformarse. Traducido por Koldo ECHEBARRIA, MAP.

DEMING, W.E. (1989), Calidad, Productividad y Competitividad. La salida de la crisis. Ed. Díaz de Santos.

Díaz, A. (1997), Estado Relacional y Nueva Gestión Pública. En Calidad y Modernización en la Gestión Puiblica, Ediciones Gestión 2000, S.A.

HERAS, M.A. (1997), •Calidad Total ¿Un mito? ¿Una moda?. Rev. AAA. ESADE, n. 76.
ISHIKAWA, K. (1989), Práctica de los circulos de Control de Calidad. Ed. TGP, S.A.

JURÁv, J.M. (1990), Jurán y el liderazgo para la Calidad: un manual para directivos. Ed. Díaz de Santos.

LOPEZ, J. (1995), Servir al ciudadano. IVAP-Instituto Vasco de Administración Pública, Ediciones Gestión 2000, S.A.

MAP-Ministerio para las AdMINISTRACIONES PÚBLICAS (1995), Gestión y evaluación de la Calidad en servicios públicos.

MENDOZA, X. (1990), ·Técnicas Gerenciales y Modemización de las AA.PP. en España. INAP, Documentación Administrativa, n. .223.

METCALF, L. y RICHARDS, S. (1989), La Modernización de la gestión priblica. INAPMAP.

OCDE (1987), La Administración al servicio del público. Ed. MAP.

Udaondo, M. (1992), Gestión de Calidad. Ed. Díaz de Santos.

Zemhmal; Parasuraman y Berry (1993), Calidad Total en Empresas de Servicios. Ed. Díaz de Santos. 
